\title{
Editorial Policies
}

This document collects the journal policies of AUDITIO. It describes the ethical standards that all participants in the submission, peer-review and publication process are expected to follow. Whether you are an author, you have been invited to review a paper for AUDITIO, or you are an associated/guest editor for one of our issues, please familiarize yourself with these guidelines.

AUDITIO is committed to follow the ethical principles adopted by the Committee on Publication Ethics (COPE) along with selected policies modified from the World Association of Medical Editors (WAME) and the International Committee of Medical Journal Editors (ICMJE).

For reference, the COPE guidelines alluded in this document can be found here in different languages: https://doi.org/10.24318/cope.2019.2.26

\section{Table of Contents}

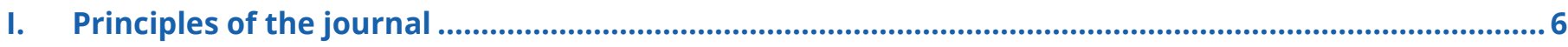

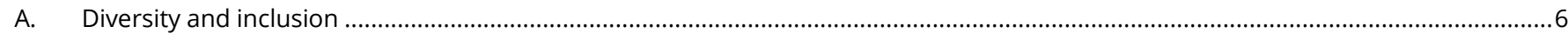

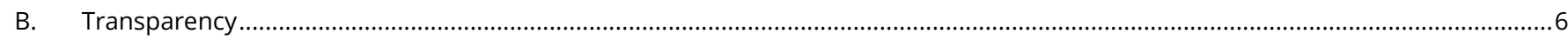

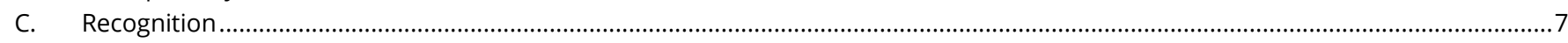

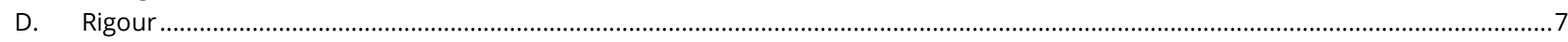

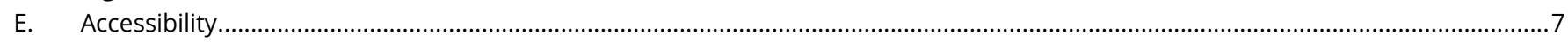

II. Editorial independency..............................................................................................................................

III. Open Access policies ........................................................................................................................................... 8

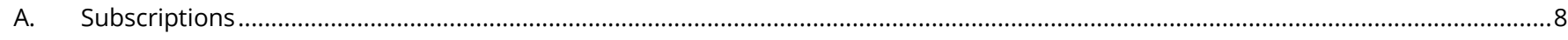

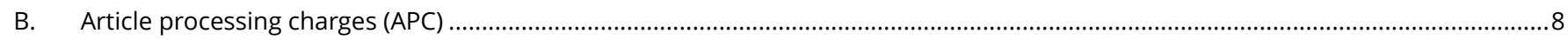

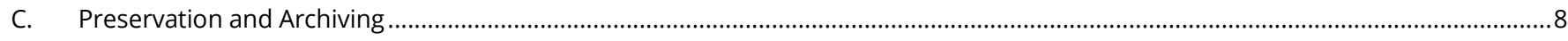

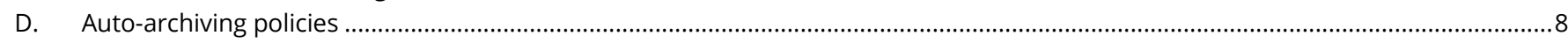

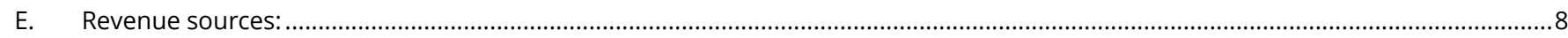

IV. General Publication policies....................................................................................................................... 9

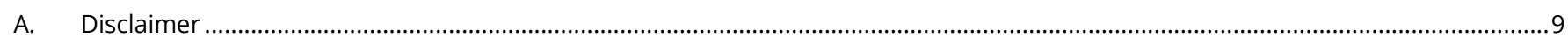

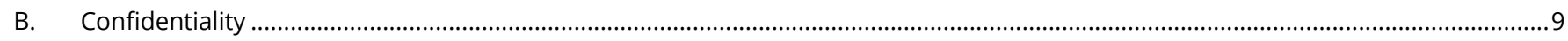

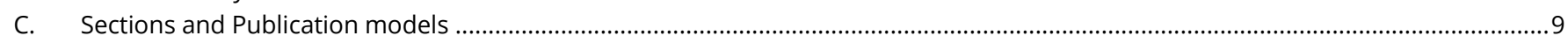

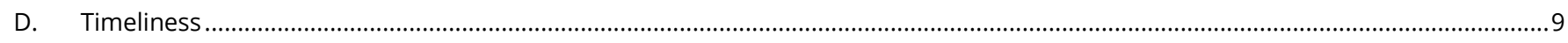

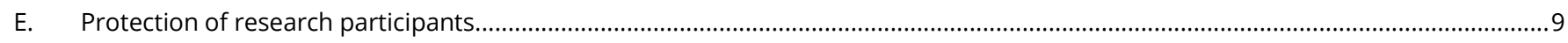

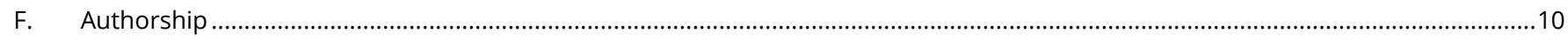

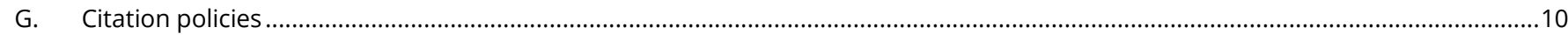

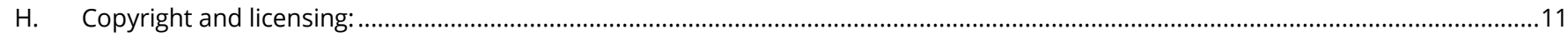

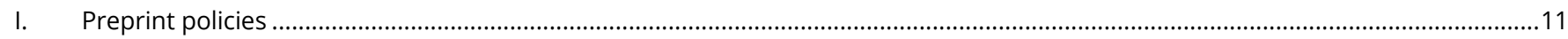




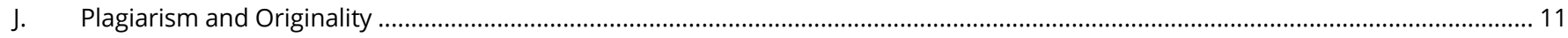

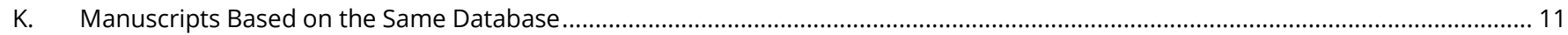

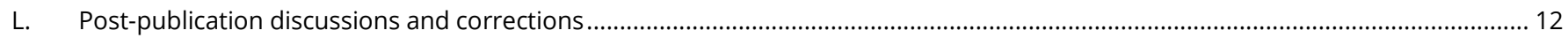

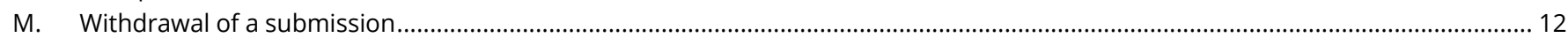

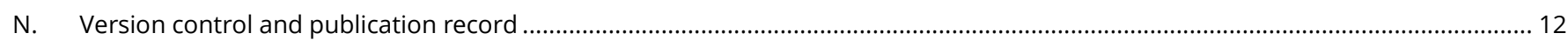

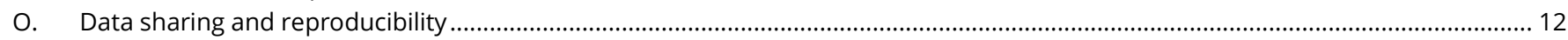

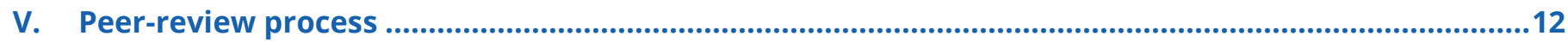

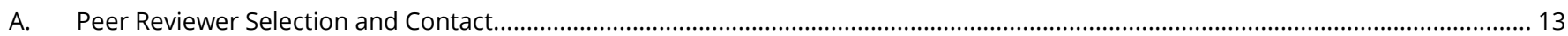

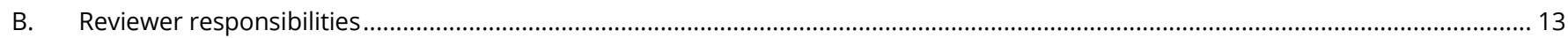

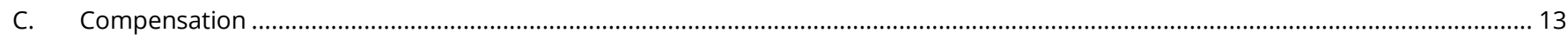

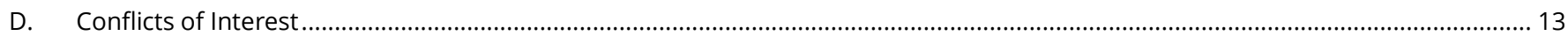

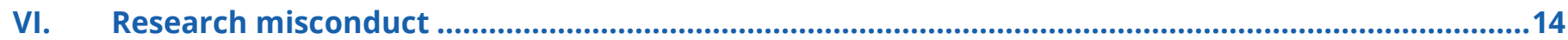

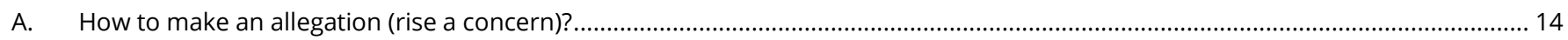

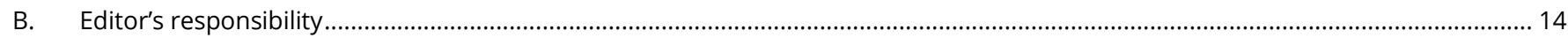

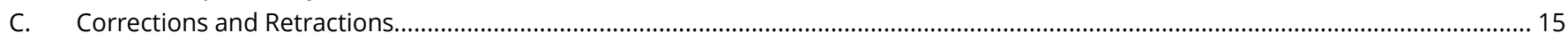

\section{Principles of the journal}

All decisions and processes in the Spanish Journal of Audiology, AUDITIO, are based on the following principles:

\section{A. Diversity and inclusion}

AUDITIO welcomes all relevant contributions and is committed to treating submissions fairly and without bias with regards to race, religion, nationality, sex, seniority, or affiliation. In addition, AUDITIO editors will seek to engage a broad and diverse array of authors, reviewers, editorial staff, editorial board members, and readers as recommended by WAME. AUDITIO also welcomes the contribution of hearing care professionals, especially in the section AUDITIO |Research Communications as authors and as no-academic reviewers, who participate actively in the peer-review process to contribute an additional point of view that increases the value of the publication.

\section{B. Transparency}

All the processes related to the editorial activity of AUDITIO will be public for the readers as long as this does not compromise confidentiality of the evaluation of the scientific contributions. The editorial office is committed to provide statistics of submitted articles as well as data about the human and economic resources of the journal. 


\section{Recognition}

AUDITIO appreciates the work of the different actors involved in the journal. AUDITIO will seek for public recognition for authors, reviewers, editors, collaborators, and funding entities if this does not affect confidentiality principles.

\section{Rigour}

The contributions considered in AUDITIO are evaluated by experts in a peer-review process. Methods, results interpretations and conclusions have to be based on the scientific method. Rigorous work will be prioritized before innovation, which means that the quality of articles with no positive results or replication studies will be welcome in AUDITIO. The scientific contributions must follow ethical standards.

\section{E. Accessibility}

The content of AUDITIO is accessible without subscription. The articles submitted from 2021 on will be available both in Spanish and English.

\section{Editorial independency}

AUDITIO is a publication of the Spanish Audiological Society (AEDA; Asociación Española de Audiología). Both the AEDA Board of Directors and the AUDITIO editorial team are committed to maintaining editorial independence (https://wame.org/editorial-independence) of the journal. All editorial decisions will be based on the quality of the contributions and rigorous peer-review, without any political, financial or personal influences related to AEDA. To establish clear boundaries between the association and the journal, the following competencies have been defined:

- Journal director / managing editor: the managing editor will be appointed by the AEDA Board of Directors in the person of a member of the Board of Directors. His/her responsibility is to ensure the quality of the publication especially regarding the quality of the production process and workflow.

- Editor in chief: the editor-in-chief will also be appointed by the AEDA board of directors, at the proposal of the managing editor who will give priority to AEDA members with recognized scientific and /or academic aptitudes for this position. His/her responsibility is to ensure the scientific quality of the publication. The positions of editor-in-chief and managing editor may be held by the same person.

- Editors: to ensure editorial independence, up to a maximum of two people can simultaneously hold a position on the editorial team (co-editors and associate editors) of AUDITIO and on the AEDA board of directors, including the Editor-in-Chief and the Director. 
- Editorial board: The role of the editorial board is to advise and provide vision on the future of the scientific journal. The members of the AEDA board of directors may not be part of the editorial board.

- Guest editors: on relevant occasions (e.g., specific research topics, special issues, etc.), members of the AEDA board of directors may act as guest editors. Their appointment will be based solely on their scientific competence and / or academic background.

In broad terms, AUDITIO follows the recommendations of COPE stated here: http://publicationethics.org/files/Learned Society Guidelines 0.pdf

\section{Open Access policies}

\section{A. Subscriptions}

All the content in AUDITIO is Open access. The articles are published under Creative Commons licenses. From 2021, the authors can choose the license at the time of the submission and/or acceptance.

\section{B. Article processing charges (APC)}

AUDITIO does not apply article processing charges (APC) to the members of the Spanish Audiological Society (AEDA). For non-members, the article processing charges are partly covered by AEDA until December 2023. The APC covers the production, translation and correction of the accepted articles and is payable only if your article is accepted. Payment will be required immediately after peer review. The APC is subject to taxes where applicable. The current APC (2021 -2023) is 150€.

\section{Preservation and Archiving}

AUDITIO is preserved in the Public Knowledge Project Preservation Network and in LOCKSS

\section{Auto-archiving policies}

AUDITIO allows the auto-archiving of the pre-print and post-print versions by the authors in public and private repositories. Authors are permitted and encouraged to post their work online (e.g., in institutional repositories or on their website) prior to and during the submission process, as it can lead to productive exchanges, as well as earlier and greater citation of published work (See The Effect of Open Access).

\section{E. Revenue sources:}

AUDITIO is a self-financed open access journal published by the Asociación Española de Audiología. Article publication charges levied to non-member authors is the only source of income which is utilized in maintaining the administrative cost. The APC is based on operating expenses including the cost of 
web maintenance, article processing, XML-JATS captures, corrections and translations. AEDA is committed to cover the 70\% of the APC until December 2023.

At the moment, AUDITIO does not receive any revenue from advertising, reprints, institutional support or subscriptions.

\section{General Publication policies}

\section{A. Disclaimer}

The responsibility for the authenticity of scientific findings, interpretations, opinions, and materials of articles published in AUDITIO are solely with the authors. The reviewers' reports result of the peerreview process that are published as supplemental material are responsibility of the authors and reviewers that participated in it.

\section{B. Confidentiality}

Manuscripts submitted to AUDITIO are privileged communications that are the authors' private, confidential property. AUDITIO will not share information about manuscripts, including whether they have been received and are under review, their content and status in the review process, criticism by reviewers, and their fate, to anyone other than the authors and reviewers.

\section{Sections and Publication models}

AUDITIO has two publication sections, AUDITIO | Research articles and AUDITIO |Research Communications. Both follow a confidential single-blind peer-review process.

\section{Timeliness}

AUDITIO is committed to process submissions in a timely manner. AUDITIO strives to notify whether the submission will proceed to review within 5 working days. A first decision, except in exceptional cases properly notified to the author, can be expected after 4-5 weeks.

\section{E. Protection of research participants}

All investigators should ensure that the planning conduct and reporting of human research are in accordance with the Helsinki Declaration as revised in 2013.

- Any manuscript submitted to AUDITIO should only contain anonymized data.

- If human subjects are participants of a research study or clinical investigation, a written consent form should always be provided and signed by the participant.

- All authors should seek approval to conduct research from an independent local, regional or national review body (e.g., ethics committee, institutional review board). 
- Approval by a responsible review body does not preclude editors from forming their own judgment whether the conduct of the research was appropriate.

- When reporting experiments on non-human animals, authors should indicate whether institutional and national standards for the care and use of laboratory animals were followed. Further guidance on animal research ethics is available from the International Association of Veterinary Editors' Consensus Author Guidelines on Animal Ethics and Welfare.

\section{F. Authorship}

Authorship confers credit and has important academic, social, and financial implications. Authorship also implies responsibility and accountability for published work. AUDITIO follows the recommendations for authorship expressed by the ICMJE (http://www.icmje.org/recommendations/browse/roles-and-responsibilities/defining-the-role-ofauthors-and-contributors.html).

The following 4 criteria must be met to be considered an author:

1. Substantial contributions to the work contained in the manuscript.

2. Critical revision of the important intellectual content.

3. Final approval of the version to be published.

4. Being accountable for the parts of the work he or she has done, an author should be able to identify which co-authors are responsible for specific other parts of the work. In addition, authors should have confidence in the integrity of the contributions of their co-authors.

Those people involved who otherwise do not meet all four criteria should be included in the acknowledgments section instead. It is the responsibility of the submitting author to provide an accurate list of co-authors.

AUDITIO does not support gift, honorary or ghost authorship as defined by the American Journal Experts (https://www.aje.com/dist/docs/Authorship Attribution EN.pdf ). Therefore, manuscripts submitted to AUDITIO are required to provide the authors contributions following the criteria of the CRediT - Contributions Role Taxonomy

\section{G. Citation policies}

AUDITIO strongly encourage the citation of primary literature, and thus has a sufficiently large limit on the number of references that can be included (50 for research articles and 30 for research communications). However, the relevance of the included citation will be assessed by the editor and the reviewers. Citation of previous work from the same author or research group should be adequately justified. AUDITIO encourages authors to include DOIs for their citations. 


\section{H. Copyright and licensing:}

Authors retain copyright and grant the journal right of first publication with the work simultaneously licensed under a Creative Commons Attribution License that allows others to share the work with an acknowledgement of the work's authorship and initial publication in this journal.

Authors may enter separate, additional contractual arrangements for the non-exclusive distribution of the journal's published version of the work (e.g., publish it in a book), with an acknowledgement of its initial publication in this journal.

\section{Preprint policies}

AUDITIO allows and encourages submissions that have been previously made available in a preprint server.

\section{J. Plagiarism and Originality}

Plagiarism is considered unacceptable. AUDITIO uses Turnitin tools over the accepted manuscripts to evaluate their originality and similarity. Direct translation with no appropriate attribution and citation will also be consider plagiarism.

AUDITIO only accepts manuscripts that are unique. I.e., authors may not submit the same manuscript, in the same or different languages, simultaneously to other journals.

Acceptable Secondary Publication is admitted in the following cases:

- Conference papers and thesis: only if additional value is added by e.g., extending the discussion or introduction sections. Appropriate reference must be made to the original work, and the author must be sure that they still hold publishing rights to the material.

- For the publication of "research reports" and "clinical reports", secondary publication will be accepted, as long as the submission aims to bring research results to a new audience, as well as that the licensing of the original publications allows for derivate work. The secondary version must inform readers that is a derived work and cite the original.

\section{K. Manuscripts Based on the Same Database}

If separate manuscripts analysing the same data (e.g., from a publicly available database) are submitted to AUDITIO, the manuscripts will be considered independently, as recommended by the ICMJE (http://www.icmje.org/recommendations/browse/publishing-and-editorial-issues/overlappingpublications.html ). Only if the submissions are substantially different to each other will they be considered for publication. If two or more articles with these characteristics are being edited by different editors and there is not sign that indicates that the authors of the manuscripts know the existence of the other's work, the Editor-in-chief might contact both parties making possible the 
discussion of each other's work. If only titles or abstracts are shared between the two groups of authors, this will not be considered a breach of confidentiality.

\section{Post-publication discussions and corrections}

Errors are part of science, therefore AUDITIO allows for corrections. Authors may contact editors to publish a note of correction as well as an updated manuscript, as long as the main conclusions and interpretations of the work are unchanged. If substantial errors that alter the conclusions of the study are found, the editors may choose to retract the manuscript. AUDITIO follows the COPE guidelines for retractions and expressions of concern (https://publicationethics.org/newsevents/cope\%E2\%80\%99sretraction-guidelines). Any concern related to an article published in AUDITIO must be communicated to the editor and publisher to initiate the corresponding investigation at manuscritos@aedaweb.com.

\section{Withdrawal of a submission}

If an author chooses to withdraw their manuscript from the peer-review process it will be archived in AUDITIO's submissions system and still bound by confidentiality. The archived version may only be accessed by external quality agencies (e.g., FECYT) with proper notification to the author.

\section{N. Version control and publication record}

All versions the articles published in AUDITIO will remain available once published unless the correction is due to a grammatical error or a typo. When multiple versions of the same article are available these articles are clearly labelled with the date of publication and version number.

\section{O. Data sharing and reproducibility}

AUTIO expects all authors to comply with data storage regulations according to their institution/funding sources. If the original data is requested by a reviewer or editor for the proper evaluation of the manuscript authors must be able to provide it or risk a rejection or retraction. By publishing in AUDITIO, authors agree that they will make their data available to qualified researchers, in a timely manner and with minimal restrictions. Authors must make datasets available in public repositories such as Zenodo.

\section{Peer-review process}

AUDITIO adopts the Ethical guidelines for peer reviewers proposed by COPE (https://doi.org/10.24318/cope.2019.1.9) with emphasis in the following specifications:

- All content published in AUDITIO is peer-reviewed except the section of journal communications which contains editorials, obituaries, announcements, notes on the journal policies, etc.

- AUDITIO editors have the right to reject a submitted manuscript before starting a formal peer review process if the submission is deemed inappropriate or outside AUDITIO's scope. 
- The reviewers get recognition of their work by appearing publicly in the article. However, their identity remains unknown by the authors during the peer-review process unless the reviewer decides to sign his/her evaluation.

- The reports from the peer-review process may be published as supplemental material if all the parties (authors and reviewers) agree that the review reports should be public due to their scientific interest. In this case the article will be labelled as "open peer-review".

\section{A. Peer Reviewer Selection and Contact}

In the sections AUDITIO | Research articles and AUDITIO |Research Communications authors will be allowed to suggest potential reviewers. The editor may choose within those suggested or contact other reviewers.

\section{B. Reviewer responsibilities}

Reviewers are bounded by confidentiality, they must follow AUDITIO's review guidelines (link). Reviewers are encouraged to evaluate the manuscript in collaboration with students and young scientist if relevant. The invited reviewer should then inform the editor to give credit and recognition to the student as well.

\section{Compensation}

Reviewers and editors do not receive any economical compensation. The main benefit of the reviewer's voluntary participation is of scientific nature. Reviewers are publicly recognized for their contribution in the published article. Furthermore, the reviewer's reports can be public after the peer-review as part of the article records or in external services such as Publons. AEDA may consider additional ways of non-economical appreciation (e.g., discounts in conferences or courses organized by AEDA)

\section{Conflicts of Interest}

AUDITIO's policies on conflict of interest are based on the recommendations by ICMJE (http://www.icmje.org/recommendations/browse/roles-and-responsibilities/author-responsibilities-conflicts-of-interest.html). The disclosure of any conflict or competing interest will not be seen, a priori, as problematic. However, the declared conflicts of interest will help the editorial team process the contributions to AUDITIO adequately. The non-disclosure of possible conflicts of interest can be a motive of rejection or retraction.

A competing or conflicting interest is defined as anything that might inappropriately influence (bias) or be perceived to influence - the full and objective presentation, review or publication of research findings or reviews. Competing interests can be financial, professional or personal, and can be held by authors, their employers, funders, reviewers, editors and editorial staff. 


\section{For authors}

Authors must include information regarding the provider of financial and material support of their research in the Funding section at the end of the manuscript. This statement should include authors' grant support, funding sources, and the provision of equipment and supplies.

\section{For reviewers}

Reviewers should declare any association with the authors of a manuscript. Additionally, reviewers should disclose any financial or professional associations that could be perceived as interfering with the objectivity of their scientific assessment of the manuscript under review. A joint-publication or a relation such as that of PhD student - supervisor, can be considered a conflict of interest if the last collaboration was published within the last 4 years.

\section{For editors}

AUDITIO editors are obliged to delegate the peer review of any original self-authored research article to another member of the editorial or advisory board. Editors (associate and invited) who make final editorial decisions on articles must have no financial, personal or professional involvement with the manuscript under consideration. If a potential bias exists, they should withdraw from handling the paper.

AUDITIO editors will always base decisions on the quality of the work and not on its potential effect on the Journal's commercial success. Publishing fees or waiver status should not influence editorial decision making.

\section{Research misconduct}

Plagiarism, citation manipulation, and data falsification/fabrication are unacceptable. In case of any suspicion or allegation of misconduct the manuscripts are treated according to the COPE guidelines (https://doi.org/10.24318/cope.2019.2.26).

\section{A. How to make an allegation (rise a concern)?}

Any author, reader, editor or reviewer of AUDITIO can submit an allegation or raise a concern related to the published or unpublished work with suspected misconduct by writing to manuscripts@aedaweb.com.

\section{B. Editor's responsibility}

Editors must act in case of suspected misconduct. The editor should not only reject the manuscript but start an investigation to pursue the alleged cases. The extend of this duty includes unpublished manuscripts. The editors should always seek for the response of the authors first, followed by the relevant employers and institutions. 
An editor can, at any time, add an expression of concern to a published article if there exist a serious allegation supported by sufficient evidence. This will inform the readers that the article is being investigated.

\section{Corrections and Retractions}

If a correction is needed AUDITIO will publish a correction notice as soon as possible detailing changes from the original publication. The correction will be included as an indexed part of the AUDITIO volumes. All previous versions of the article will be archived and available in www.auditio.com.

Retraction with republication (also referred to as "replacement") can be considered in cases where honest error (e.g., a misclassification or miscalculation) leads to a major change in the direction or significance of the results, interpretations, and conclusions.

\section{CONTRIBUTORS}

Document preparation: Helia Relaño-lborra.

Document Revision: Raul Sanchez-Lopez, Miriam I. Marrufo-Pérez.

Other contributions: Paula Hernández-Ricoy, Gerard Encina-Llamas, Carlos Benitez -Barrera, Oscar M. Cañete, Waldo Nogueira-Vázquez

PUBLISHED: $\quad 17^{\text {th }}$ May 2021 